\title{
Peluang Efisiensi Tungku Pembakaran Bata Merah di Daerah Setiti Kabupaten Muaro Jambi
}

\author{
Myson \\ Program Studi Teknik Listrik Fakultas Teknik Universitas Batanghari Jambi \\ Email : myson_ade1@yahoo.com
}

\begin{abstract}
ABSTRAK
Tahapan pembakaran bata merah dimulai dari penguapan (pengeringan) pada temperatur kira-kira $120^{\circ} \mathrm{C}$. Selanjutnya tahap oksidasi dimana terjadi pembakaran sisa-sisa karbon yang terdapat didalam tanah liat. Proses ini berlangsung pada temperatur $650^{\circ} \mathrm{C}-800^{\circ} \mathrm{C}$. Kemudian pembakaran penuh. Bata merah dibakar hingga matang dan terjadi proses sintering hingga menjadi bata padat. Temperatur matang bervariasi antara $920{ }^{\circ} \mathrm{C}-1020{ }^{\circ} \mathrm{C}$ tergantung pada sifat tanah liat yang dipakai. Dari data diketahui daerah sekitar tungku, setelah semua bahan bakar terbakar. memiliki temperature diatas $300{ }^{\circ} \mathrm{C}$, sehingga hal ini merupakan suatu peluang untuk memperpendek waktu proses pengeringan. Untuk dapat memanfaatkan panas tersebut yang biasanya terbuang diperlukan beberapa perubahan yaitu perubahan pada sistim dan arah penjemuran bata merah mentah serta perubahan pada tungku pembakaran.
\end{abstract}

Kata kunci : Efisiensi, Tungku, Pembakaran, Bata merah

\section{PENDAHULUAN}

Membangun rumah menggunakan bata merah merah merupakan sesuatu yang biasa dan lumrah ditengah-tengah masyarakat kita. Material bata merah merah selain harganya yang terjangkau, juga memiliki kelebihan jika dibandingkan dengan menggunakan material bangunan lainnya seperti batako, batu hebel atau bata ringan serta material bangunan lainnya. Salah satu kelebihannya adalah dari sisi keindahan dan harga yang lebih murah. Menggunakan bahan bangunan bata merah memang memiliki kekhasan sendiri. Penggunaan bata merah banyak digunakan untuk dinding pada bangunan perumahan, gedung, pagar, saluran drainase ataupun pondasi. Pesatnya pembangunan di sektor perumahan dan property menjadikan kebutuhan akan bata merah semakin meningkat.

Hal lain yang menjadikan komoditas ini banyak dikerjakan, karena proses pembuatannya yang relatif mudah dengan biaya investasi yang rendah dan bahan baku mudah didapat. Peralatan yang diperlukan pun sederhana mulai dari peralatan tradisional seperti cangkul, alat pencetak bata merah atau mesin press, mesin penggiling bata merah, mesin pembakar atau bisa juga menggunakan tungku pembakaran, kayu bakar, batu bara atau sekam padi. Sedangkan bahan bakunya dari tanah liat, air dan abu sisa pembakaran. Proses pembuatan bata merah juga sangat sederhana, yaitu tanah liat yang sudah diramu dicetak dalam mesin pencetak, selanjutnya di jemur lalu dibakar.

Pembuatan bata merah merah melalui proses pembakaran berpotensi menimbulkan pencemaran udara. Disamping itu bahan bakar berupa kayu bakar yang saat ini terus menipis jumlahnya sehingga harga bahan bakar kayu menjadi relatif lebih mahal sehingga biaya produksi pun menjadi mahal. Dari sisi lingkungan hal ini sangat ditentang.

Proses pembakaran dilakukan selama 5 hingga 7 hari tanpa henti (non stop), hal ini bergantung pada jenis bahan bakar yang digunakan. Setiap kali pembakaran umumnya terdapat 30.000 hingga 100.000 bata merah. Namun ada juga tungku pembakaran yang kapasitasnya lebih besar mencapai 200.000 bata merah. Dengan demikian jumlah bahan bakar kayu juga akan semakin banyak dibutuhkan.

Bahan bakar yang digunakan bermacam-macam, diantaranya adalah potongan limbah pohon kayu, limbah kayu dari bangsal konsen dan ada juga yang menggunakan batu bara. Jika kondisi cuaca cerah (musim kemarau), pembakaran dapat dilakukan setiap 20 hari sekali, namun apabila kondisi cuaca musim penghujan, maka pembakaran hanya dapat dilakukan 1 kali dalam 1 bulan atau lebih. Bata merah yang di cetak berukuran sedang yaitu 9 × 9 x $19 \mathrm{~cm}$. Namun setelah pembakaran ukuran akan mengalami penyusutan hingga 20\%. Untuk menghindari penyusutan ada beberapa produsen bata merah yang 
menambahkan penyusutan tersebut pada saat pencetakan. Dengan demikian akan dibutuhkan jumlah bahan baku tanah liat yang lebih banyak yaitu lebih kurang $20 \%$.

Tujuan dari penelitian ini adalah: 1) Untuk mengetahui sejauh mana penggunaan panas pada proses produksi bata merah merah yang terjadi pada masyarakat produsen di daerah Setiti kabupaten Muaro Jambi; 2) Untuk mengetahui teknologi yang digunakan masyarakat produsen bata merah merah di daerah Setiti kabupaten Muaro Jambi; 3) Memberikan masukan kepada masyarakat produsen bata merah merah terkait dengan penggunaan panas yang dihasilkan dari pembakaran bahan bakar kayu di daerah Setiti kabupaten Muaro Jambi.

\section{Pembakaran Bata Merah}

Selama proses pembakaran terjadi perubahan fisika dan kimia serta mineralogi dari tanah liat sebagai bahan baku bata merah. Proses pembakaran ini harus berjalan seimbang dengan kenaikan suhu. Dalam proses pembakaran bata merah berlaku Hukum Termodinamika II dan juga modulus-modulus perpindahan panas seperti konduksi, konveksi dan radiasi Serta pengaruh waktu terhadap laju aliran termal seperti steady dan transient

a. Dalam hukum termodinamika II tentang hukum kesetimbangan yaitu kenaikan entropi panas tidak bisa mengalir dari material yang dingin kematerial yang panas secara spontan.

b. Konduksi - Perpindahan kalor secara perambatan atau konduksi adalah perpindahan kalor dari suatu bagian benda padat ke bagian lain dari benda padat yang sama, atau dari benda padat yang satu ke benda padat yang lain karena terjadi persinggungan fisik.

c. Konveksi - Perpindahan kalor secara aliran atau konveksi adalah perpindahankalor yang dilakukan oleh molekul-molekul suatu fluida (cair atau gas). Molekul-molekul fluida tersebut dalam gerakannya melayang kesana-kemari membawa sejumlah kalor

d. Radiasi - Perpindahan kalor secara pancaran atau radiasi adalah perpindahan kalor suatu benda ke benda yang lain melalui gelombang elektromagnetik tanpa medium perantara. Bila pancaran kalor menimpa suatu bidang, sebagian dari kalor pancaran yang diterima benda tersebut akan dipancarkan kembali (reradiated), dipantulkan (reflected) dan sebagian dari kalor akan diserap

e. Stedi - Perpindahan panas yang tidak berpengaruh terhadap fungsi waktu.

f. Transien - Perpindahan panas yang berpengaruh terhadap fungsi waktu.

Dalam proses pembakaran bata merah tahapan yang harus dilalui adalah sebagai berikut :

1. Tahap pertama adalah penguapan (pengeringan), yaitu pengeluaran air pembentuk bata merah merah yang terjadi pada temperatur kira-kira $120^{\circ} \mathrm{C}$.

2. Tahap oksidasi, terjadi pembakaran sisa-sisa tumbuhan (karbon) yang terdapat didalam tanah liat. Proses ini berlangsung pada temperatur $650^{\circ} \mathrm{C}-800^{\circ} \mathrm{C}$.

3. Tahap pembakaran penuh. Bata merah merah dibakar hingga matang dan terjadi proses sintering hingga menjadi bata padat. Temperatur matang bervariasi antara $920{ }^{\circ} \mathrm{C}-1020{ }^{\circ} \mathrm{C}$ tergantung pada sifat tanah liat yang dipakai.

4. Tahap penahanan. Pada tahap ini terjadi penahanan temperatur selama 1-2 jam.

Pada tahap 1,2 dan 3 kenaikan temperature harus perlahan agar tidak terjadi pecah, noda hitam, penyusutan dan lain-lain.Temperature dalam tungku dinaikan dengan cara menambah kayu bakar yang dimulai dari temperature kamar sampai $120^{\circ} \mathrm{C}$ (untuk menghilangkan sisa air yang ada) kemudian, dilanjutkan dengan $800^{\circ} \mathrm{C}$ (dipertahankan dengan waktu tertentu) dengan tujuan menghilangkan karbon pada abu serta menghilangkan molekul-molokul. Kemudian dinaikan ke temperatur 950-1000 ${ }^{\circ}$. Tidak jarang temperature dinaikan lagi hingga $1020^{\circ}$ untuk mendapatkan standar SNI. Hal ini terjadi karena semakin tinggi temperaturnya maka tanah akan mendekati sifat keramik dimana partikel-partikelnya hampir mengalami ikatan yang sempurna. Partikel-partikel mengalami perubahan bentuk yang saling mengisi poripori sehingga bata merah akan kuat dan keras. 


\section{Tungku Pembakaran}

Proses pembakaran merupakan langkah yang sangat penting dalam memproduksi bata merah merah. Dalam proses pembakaran dibutuhkan tungku pembakaran yang sesuai dengan jumlah bata merah mentah yang akan dibakar. Untuk mendapatkan hasil yang maksimal perlu diperhatikan distribusi panas pada tungku yang merata. Hal ini akan berdampak pada kualitas bata merah dan mengurangi jumlah bata merah yang gagal dalam proses pembakaran. Semakin tidak merata semakin besar persentase tingkat kegagalan produksi.

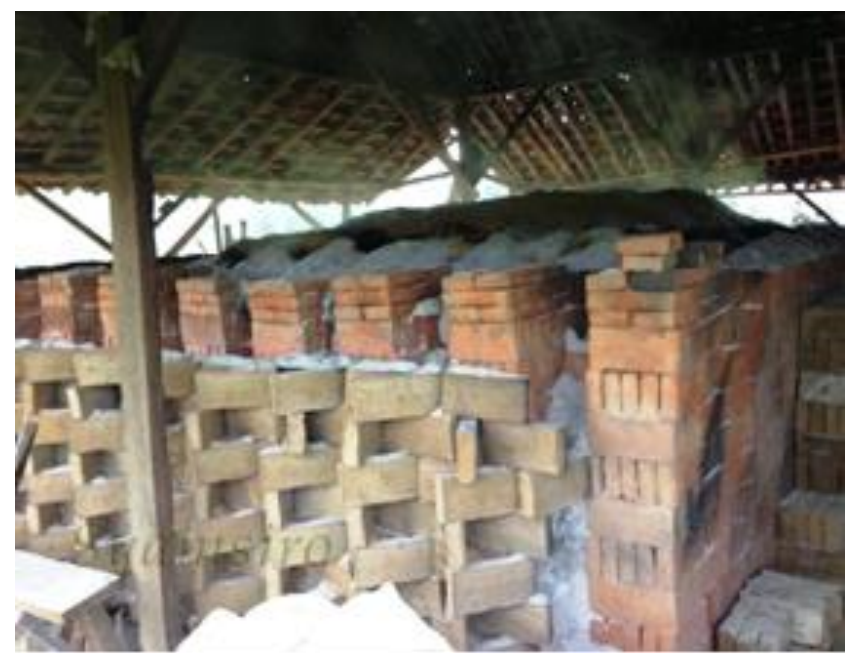

Gambar 1. Tungku pembakaran bata merah

\section{METODE PENELITIAN}

Penelitian ini akan melakukan eksperimen langsung pada masyarakat produsen bata merah. Adapun data yang dibutuhkan adalah temperature mulai dari lorong sumber api hingga ujung tungku. Kemudian mendapatkan temperatur dinding dan atap (penutup) tungku. Data ini di butuhkan guna mengetahui distribusi panas yang terjadi pada proses pembakaran bata merah.

\section{HASIL DAN PEMBAHASAN}

Proses pemanasan berguna untuk menurunkan kadar air yang ada pada bata merah mentah. Proses ini dilakukan dengan pembakaran yang bertemperatur rendah sekitar $300^{\circ} \mathrm{C}$. Hal ini berfungsi untuk menjaga kenaikan temperature yang sangat tinggi yang akan berakibat pada gagalnya pembuatan bata merah tersebut. Proses ini dilakukan dengan melakukan pembakaran kedua ujung mulut lorong api pada tungku tersebut.

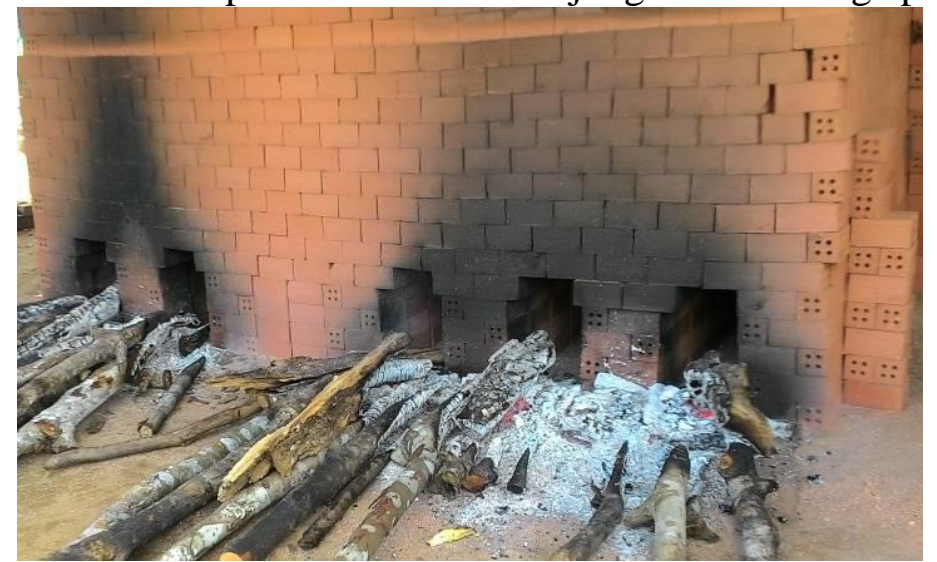

Gambar 2. Pemanasan pada ujung lorong api bagian utara 


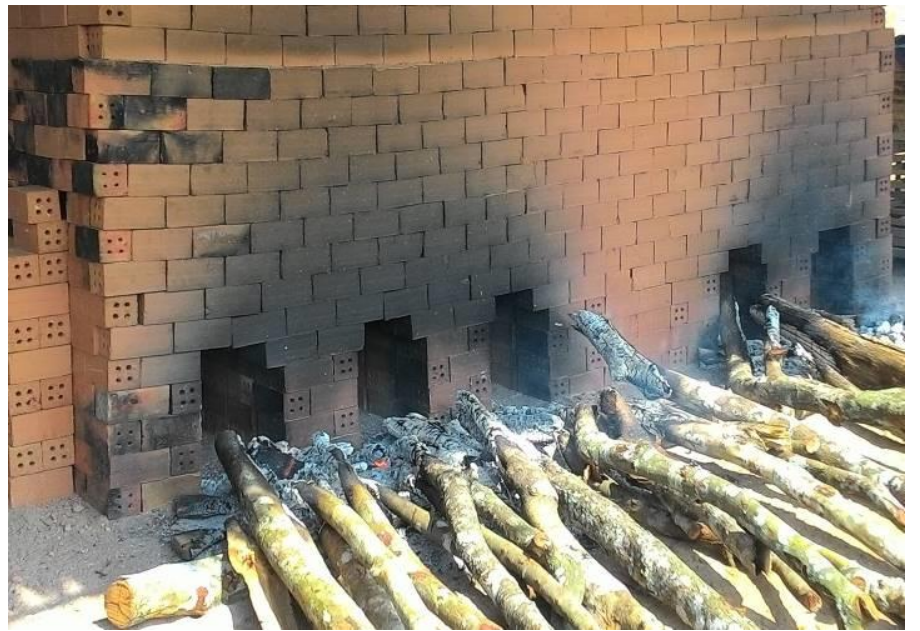

Gambar 3. Pemanasan pada ujung lorong api bagian selatan

Kayu bakar sebagai bahan bakar diletakan diluar masing masing ujung lorong api. Dengan cara ini temperature tidak akan naik jauh diatas yang diharapkan yaitu sekitar $300{ }^{\circ} \mathrm{C}$ hingga $400{ }^{\circ} \mathrm{C}$. Ini dapat dilihat pada gambar dibawah ini.

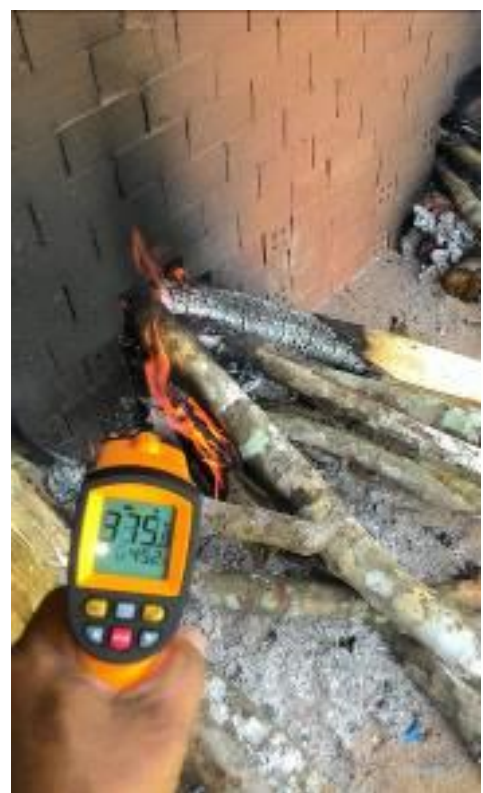

Gambar 4. Suhu mulut lorong api

Dari gambar diatas terlihat bahwa temperature berada pada $375^{\circ} \mathrm{C}$. Pada proses pemanasan atau yang biasa disebut oleh para pembuat bata merah tradisional dengan pengasapan terkadang api kayu bakar juga mengalami padam. Namun hal ini tidaklah berdampak langsung pada proses pembuatan bata merah tersebut. Proses pemansan ini dilakukan dari dua sisi pada masing-masing lorong api yang ada. Proses ini membutuhkan waktu sekitar dua hingga tiga jam tergantung kadar air yang terkandung pada mata merah mentah. Makin kering bata merah mentah tersebut, maka makin pendek waktu yang dibutuhkan untuk proses pemanasan atau pengasapan.

Setelah mengalami pemanasan maka sekitar daerah tersebut akan menjadi sangat kering dan bata merah telah mengalami penyusutan secara perlahan. Daerah tersebut dapat diberi api dengan tempertur yang lebih tinggi. Temperatur tersebut meningkat dari $300{ }^{\circ} \mathrm{C}$ atau $400{ }^{\circ} \mathrm{C}$ meningkat secara cepat menjadi $800{ }^{\circ} \mathrm{C}$ hingga $900^{\circ} \mathrm{C}$ hanya dalam 3 hingga 4 jam. Hal ini dapat dilihat pada gambar dibawah ini. 


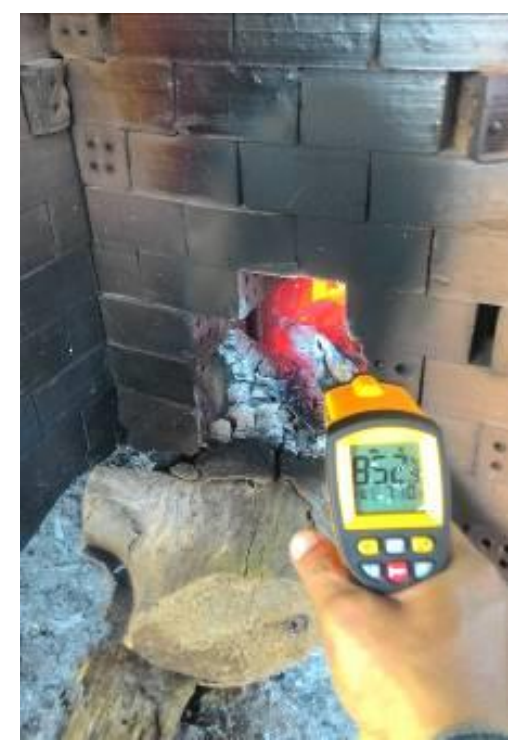

Gambar 5. Temperatur dalam mulut lorong api

Temperatur ini ditahan lebih kurang dua jam sehingga daerah ujung yang belum terkena pemanasan atau pengasapan akan mengalami pengeringan, sehingga seluruh tungku dapat mengalami proses pemanasan dan temperature dapat dinaikan menjadi $800{ }^{\circ} \mathrm{C}$ hingga $900{ }^{\circ} \mathrm{C}$ hingga seluruh tungku mencapai temperature tersebut. Temperatur ini ditahan hingga seluruh bahan bakar yang telah disusun dalam tungku bata marah, baik yang ada di lapis kedua, lapis ketiga maupun lapis ke empat menjadi terbakar juga. Jika sudah demikian maka temperature dalam tungku akan meningkat menjadi diatas diatas $900{ }^{\circ} \mathrm{C}$ hingga diatas $1350{ }^{\circ} \mathrm{C}$.
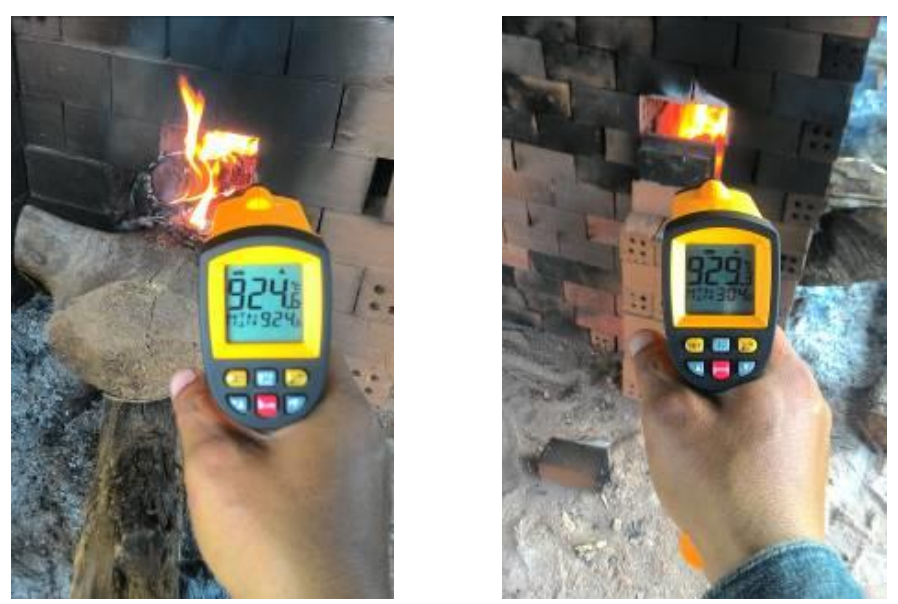

Gambar 6. Temperatur dalam tungku yang sudah sangat panas

Namun karena keterbatasan alat yang hanya mampu membaca sampai $950{ }^{\circ} \mathrm{C}$ saja, maka datanya tidak dapat ditampilkan.

Temperatur ini akan bertahan hingga seluruh bahan bakar kayu yang ada dalam tungku terbakar habis. Waktu yang dibutuhkan untuk menghabiskan bahan bakar kayu yang ada didalam tungku ditentukan oleh banyaknya bahan bakar kayu yang dimasukan kedalam tungku, namun biasanya untuk menghemat bahan bakar, biasanya cukup dengan waktu satu hari penuh atau sekitar 12 jam. 


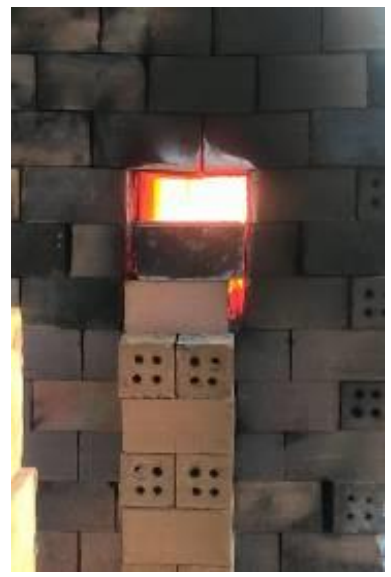

Gambar 7. Warna api yang sangat panas didalam tungku

Dalam proses pembakaran suhu yang dihasilkan pada bagian dalam tungku berada sekitar $1050{ }^{\circ} \mathrm{C}$ hingga $1350{ }^{\circ} \mathrm{C}$. Ini dapat dilihat dari pembacaan alat ukur yang tidak mampu membaca temperature diatas $960{ }^{\circ} \mathrm{C}$.

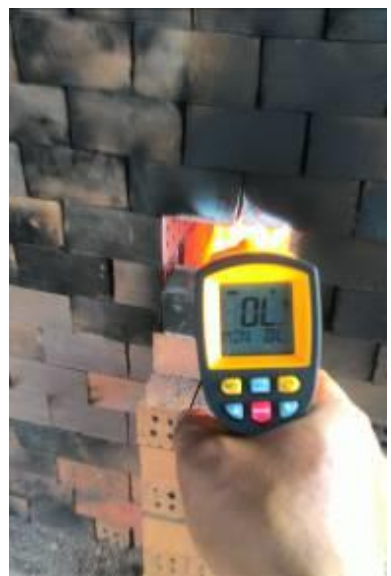

Gambar 8. Keterbatasan alat yang tak mampu membaca suhu diatas $950{ }^{\circ} \mathrm{C}$

Dari panas yang dihasilkan ini sebagian akan terpancarkan keluar akibat dari disain tungku tersebut. Tungku disini didesain dengan sistim yang dapat dibongkar atau tidak permanen. Tujuan dari penggunaan tungku seperti ini adalah untuk memudahkan proses pascapembakaran.

Panas yang terjadi saat proses pembakaran dengan temperature yang berada diatas $1050{ }^{\circ} \mathrm{C}$ tersebut dapat dilihat dari celah-celah dinding tungku seperti gambar dibawah ini.

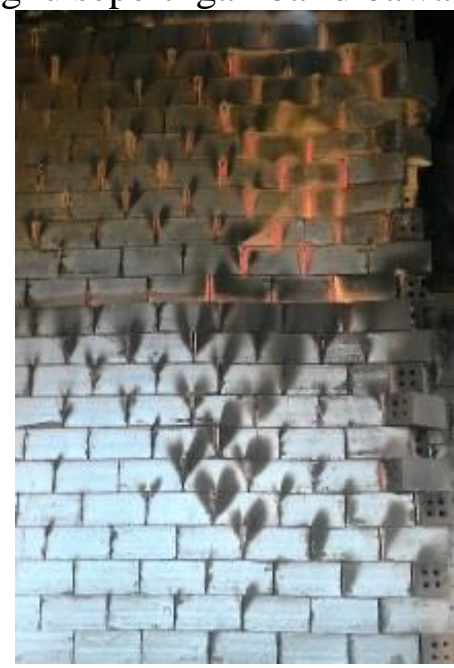

Gambar 9. Warna merah pada celah bata merah saat pembakaran 
Panas yang terpancarkan keluar dari celah-celah dinding tungku tersebut berkisar pada suhu $284{ }^{\circ} \mathrm{C}$ hingga $323{ }^{\circ} \mathrm{C}$. Ini dapat dilihat pada gambar dibawah ini.
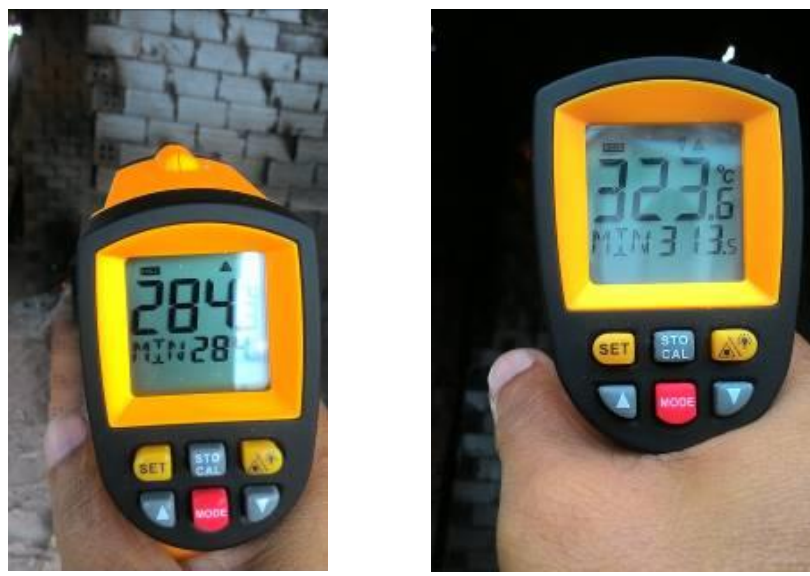

Gambar 10. Temperatur dinding tungku pembakaran bata merah

Panas ini terbuang sia-sia kelingkungan dan bahkan mencemari lingkungan dengan menaiknya suhu lingkungan sekitar tungku. Suhu yang tinggi tersebut seharusnya dapat dimanfaatkan untuk mempersingkat proses pengeringan yang selama ini hanya mengandalkan panas dari matahari yang suhunya paling tinggi didaerah tersebut berkisar $40{ }^{\circ} \mathrm{C}$ hingga $45^{\circ} \mathrm{C}$.

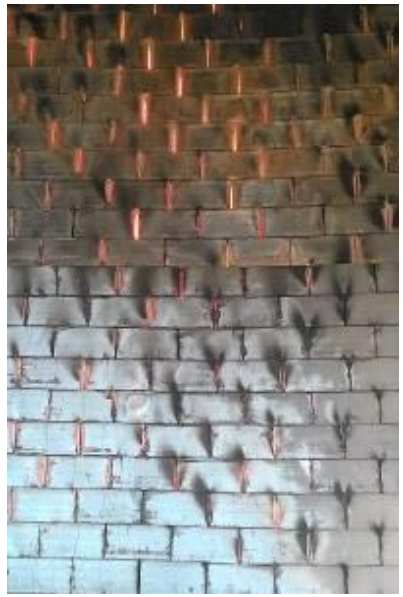

Gambar 11. Panas yang keluar tungku melalui celah bata merah saat pembakaran

Pada proses pendinginan, setelah dibakar pada suhu atau temperature hingga mencapai diatas 1050 ${ }^{\circ} \mathrm{C}$ membutuhkan waktu yang juga cukup lama. Ini terjadi karena proses pendinginan dilakukan secara perlahan dengan memanfaatkan udara dingin sekitar tungku yang berhembus. Proses pendinginan secara perlahan ini bermanfaat untuk mencegah rusaknya bata merah yang dihasilkan. Dilapangan proses pendinginan secara perlahan ini membutuhkan waktu hingga tujuh hari. Pada hari pertama hingga hari ketiga tungku masih memiliki temperature yang cukup tinggi, sehingga temperature dinding tungku dan sekitar tungku juga mengalami temperature tinggi. 


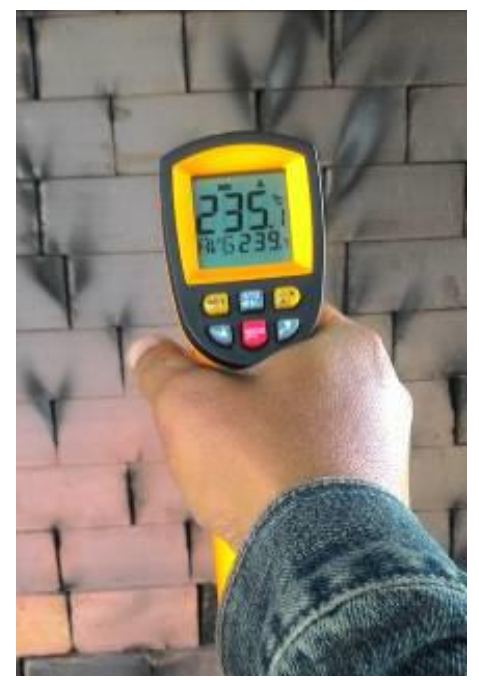

Gambar 12. Temperatur dinding saat proses pendinginan

\section{Peluang Pemanfaatan Panas Sekitar Tungku}

Dari pengambilan data diketahui bahwa panas yang ada disekeliling tungku pembakaran bata merah pada saat proses pembakaran dan proses pendinginan adalah antara $284{ }^{\circ} \mathrm{C}$ hingga $323{ }^{\circ} \mathrm{C}$. Dengan suhu yang ada di sekeliling tungku yang bertahan hingga 5 hari dari proses pembakaran dan proses pendinginan, maka merupakan potensi yang sebenarnya dapat dimanfaatkan.

Adapun peluang pemanfaatan panas dinding sekeliling tungku dapat dimanfaatkan untuk membantu mempersingkat proses pengeringan bata merah mentah yang yang secara tradisional dilakukan dengan proses penjemuran agar nantinya dapat dibakar. Pada proses pengeringan dengan sinar matahari membutuhkan waktu yang sangat lama hingga 30 hari. Proses pengeringan ini menghambat siklus produksi bata merah karena hanya dapat melakukan satu kali produksi dalam waktu satu bulan. Dengan demikian dalam satu tahun hanya dapat berproduksi sebanyak 12 kali dan dalam satu tahun terdapat 4 hingga 5 bulan berada pada musin penghujan. Hal ini menjadi problem tersendiri pada proses produksi bata merah dan akan memperlambat proses pengeringan yang berdampak pada jumlah produksi dalam satu tahun.

Panas pembakaran yang terpancar pada dinding tungku dapat dimanfaatkan dapat mempersingkat proses pengeringan sedikitnya $50 \%$ dari waktu proses produksi. Dengan terlaksananya pemanfaatan sisa panas ini maka proses produksi dapat meningkat menjadi 2 kali nya atau 24 kali produksi dalam satu tahun. Dengan demikian maka bata merah yang dapat dijual juga akan meningkat 2 kali lipat.

\section{SIMPULAN}

Dari data primer yang didapatkan pada penelitian ini diketahui bahwa daerah sekitar tungku memiliki temperature yang sangat panas dan dari data pengukuran diketahui bahwa temperature setelah semua bahan bakar terbakar berada diatas $300{ }^{\circ} \mathrm{C}$, sehingga hal ini merupakan suatu peluang untuk mengurangi waktu proses produksi bata merah pada bagian pengeringan. Dengan termanfaatkannya panas sisa ini dengan mengasumsikan pemanfaatan hanya pada 50\%, dapat dihasilkan produksi bata merah hingga $200 \%$ per tahun. Pemanfaatan ini memang membutuhkan investasi tambahan yang cukup besar untuk ukuran pabrikan bata merah tradisional, namun dengan bantuan pemerintah hal ini dapat dimanfaatkan.

Untuk dapat memanfaatkan panas sisa yang biasanya terbuang dari sekitar tungku pembakaran bata merah diperlukan beberapa perubahan. :

1. Perubahan pada sistim dan arah penjemuran bata merah mentah

2. Perubahan pada sistim tungku pembakaran bata merah

Dengan melakukan perubahan pada kedua poin diatas, maka penulis menyakini akan terjadi peningkatan jumlah produksi dan kualitas bata merah yang dihasilkan. 


\section{DAFTAR PUSTAKA}

Van Vlack, Lawrence. H. 2004. Elemen - Elemen Ilmu Dan Rekayasa Material. Jakarta: Erlangga Adrian Bejan, 1988, 'Advanced Engineering Thermodynamics', Jhon Wiley\&son.Inc

Hasan Basri, Dr.Ir, 2007, Teknik Kogenerasi (bahan kuliah), PPs Unsri, Palembang.

Roger Kinsky M.Eng,Sc.,B.E.,B.Sc, 'Applied Heat', An Introduction to thermodynamics, Second edition.

Suasmoro, Dr. 2000. Fisika Keramik. Surabaya. Jurusan Fisika FMIPA ITS.

Aji, Setyo.B dan Anjar. 2009. The Role Of a Coal Gasification Fly Ash as Clay Addive in Building

Ceramic. Journal of the European Ceramic Sosiety 26 (2006) 3783-3787.

Nelly, Komang Sundari 2010. Pengaruh Perlakuan Suhu Bakar Pada Massa Bodi Keramik Stone Kode BL 1

Terhadap Parameter Penyusutan dan Peresapan Air. Bali: Skripsi.

P.U. 1991. SNI 15 -2094 -1991 tentang Bata Merah Pejal. Jakarta: Pekerjaan Umum.

Subiyanto, Hari Subowo. 2003. Pengaruh Temperatur Sintering terhadap Sifat Mekanik Keramik Insulator

Listrik. Surabaya: ITS.

Surdia, Tata dan Kenji Chijiwa. Pengetahuan Bahan Teknik. Jakarta: Pradya Paramita, 2006.

Prayitno, Dody. Teknologi Rekayasa Material. Jakarta: 2010

Rahmat Muhammad Rais, "Perancangan Dan Pembuatan Tungku Heat Treatment" Jurnal Imiah Teknik

Mesin, Vol. 3, No.2 Agustus 2015 Universitas Islam 45 Bekasi, http://ejournal.unismabekasi.ac.id 